\begin{tabular}{|c|c|c|c|c|}
\hline $\begin{array}{l}\text { 活动 } \frac{\text { 与 }}{\text { 急定程度 }} \\
\end{array}$ & \multicolumn{2}{|c|}{ 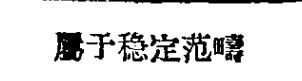 } & \multicolumn{2}{|c|}{ D于活动范略 } \\
\hline & 稳定区 & 牛稳定区 & 牛活动区 & 活 动区 \\
\hline I & 地台区 & 活化地台 & 准地槽区 & 地槽区 \\
\hline II & 台 块 & $\begin{array}{l}\text { 洁化台块 } \\
\text { 区 }\end{array}$ & 准地慒系 & 地 槽 潘 \\
\hline III & $\begin{array}{l}\text { 台背斜和 } \\
\text { 台向斜 }\end{array}$ & $\begin{array}{l}\text { 活化台背 } \\
\text { 斜和活化 } \\
\text { 台问斜 }\end{array}$ & $\begin{array}{l}\text { 准槽背斜 } \\
\text { 利准槽向 } \\
\text { 斜 }\end{array}$ & $\begin{array}{l}\text { 槽背斜和 } \\
\text { 槽向斜 }\end{array}$ \\
\hline IV & $\begin{array}{l}\text { 台凹和台 } \\
\text { 品 }\end{array}$ & $\begin{array}{l}\text { 活化台凸 } \\
\text { 和活化台 } \\
\text { 四 }\end{array}$ & $\begin{array}{l}\text { 准槽凸和 } \\
\text { 准慒凹 }\end{array}$ & $\begin{array}{l}\text { 橧凸和销 } \\
\text { 出 }\end{array}$ \\
\hline V & 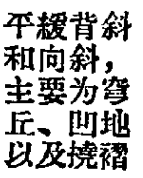 & $\begin{array}{l}\text { 短軸背斜 } \\
\text { 和问斜 }\end{array}$ & $\begin{array}{l}\text { 脣軸背斜 } \\
\text { 和向斜 }\end{array}$ & $\begin{array}{l}\text { 綫泾紧湿 } \\
\text { 背斜和向 } \\
\text { 斜 }\end{array}$ \\
\hline
\end{tabular}

不同。此外，地槽区和地台区断裂紫內的內生矿非多
成带爿分分杀，而地台㐫的則多成杯狀或片狀，这也是我 僻稀制大比例尺大地構造图时应加注意的。

必須指出, 在一張大地構造图內不能把所有的構 造細节及其发展过程都无遺地表示山来。因此, 在必 要的时候, 还应加糄一些輔助性的附图, 如基底以及 不同时期的沉积盖层的等深棧图、各时期的岩相分布 和厚度图，以及各主要構造阶段的古構造图等。

[1] Marshell Kay: North American Geosynelines, Mem. 48, USA, 1951.

[2] 燕汲清(1954): 中国区域地筫的特征，地箕学报， 34 炝, 3 期, 1954 年。

[3] 黄汲清(1958): 編制中国大地粠造图的若干澺見及 簡則(草案), 1958 年。

[4] IO. M. 謝音曼(1937)：論中国地盾的历史、地苋 发展的規律性与区域大地構造, 科学出版社, 1955年。

[5] B. M. 西尼村 (1948): 中国陆台的掼造及其发展， 周上。

[6] 陈国达(1956)：中国地台“活化区的实例讲着重时 論华夏古陆”問題，地筫学报，36 卷，3期, 1956 年。

[7] A. B. 翌偉: 深大断裂的特点、分类及其在究间 上的分右，地筫譯䂭，11 期，1956 年。

\title{
苏联科学家論宇宙火箭 和宇宙飞行
}

編者按：浫联守宙火箭上天，使疾勁的东风进一步压倒西风。这是人类放射到 地球引力范圍之外的守宙空間的第一个火箭, 它不仅为人类带来大量的有关宇宙空 間的宝貴資料, 而且也为星际航行和开发球以及其他行湦打汧了道路。最近, 苏


要諭点整理荣輯如下。

\section{苏联的宇宙火箭是現代 科学技术上的奇跡}

布拉岡拉沃夫(苏联科学院院士)：空崩的速度、 惊人的重星和完全准确的飞行控例，是苏联火箭技术

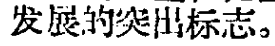

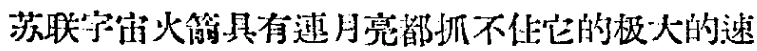
度，因此它不会变成永久葍繞月球运轉䋇卫星，它將 越过月亮繼續作太阳系的宇宙中飞行。这是世界上第


破地球引力的地球上的物体。这是苏联火简技术发展 的第一个絴朋标志，苏联科学和技术已經走在美国前 面。大家知道，美国在这方西作了几次尝陚，都长收 了; 歨年10月美国向月球发射的火简自于地球引力的 影响沟有达到月球地区就鉒落了。

第二个表归苏联佔先的合人信服的标志是, 以弚
所发射的苏联人造卫星的重量和將近一吨牛的月球火 简的重量。而美国最后一个人造卫星的重量还赶不上 苏联第一个人造卫星。

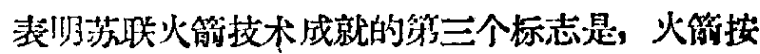


简。只要火简最后一刹进入軌道的时間稍微差錯几分 剑或速度上有細小差錯,就会导致失敗。美国1958年10 月发射的月球火箭在速度上只失去了百分之二便遭到 火敗。苏联和学家和工程师們已經解决了控制火箱飞 行的最艰难的任务。仪器工作的准确性是苏联火籍技 术的異常重要的新进步。宇宙空間没有不可能达到的 地方。当然, 这需要时間, 但是不必等待多久了。


访火简的五人体积。苏联第三个卫星就有約四公尺 㙂、二公尺的直徑(不算突出的天的)，而宇宙火箱的 重量还超过这个卫是，作这样大和重的火箭上完全可 
能校备供荫三个人居任的任所。

英国到目前还海有取得象苏联这样的成就。从关 国大陆发射的火箭远远洛有达到月球引力区。看束不 仅美国火箭的发动机，而且它的无綫电脂子操縱也沅 远地比茄联遜色。

火箭的微备比苏联第三个卫星的科学設备无疑是

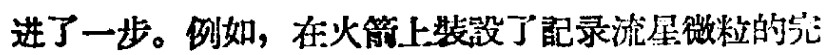
等仪器。这些資料是組織行星际旅行所必需的，因为根 据这些資料可以繪计宇宙空間中流星登的图。有一利

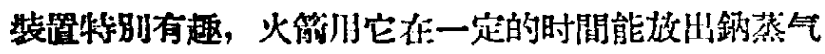
云。这个能发江人造慧星的苏联火简可川添腿和天文 仪器观察。因此未来的宇宙飞船可能是矿以看到的。

㴓斯米扬锘夫(苏联科学院院辰): 飞问月球的火 籍是現代自动化技术的奇迹。火筬初速超过倐秒才一 公里, 它是一个裝备完善的科学实驗堂, 何以研觉流

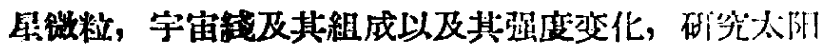
幅射而不受比球大气层孱障影响，一系列关于月球物 理情况的重大情报就將得到。对于“无人的泞宙飞船和

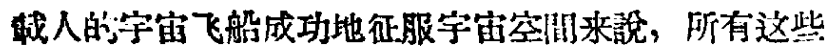
资料都是必䈏的。

托布切夫(苏联科学院副院长)：新行星一一苏联 邻一个人造太阳卫星集中了无綫电电子学、遥控力学、 冶金学、化学、自动裝置、热工学和許多其他部门”的

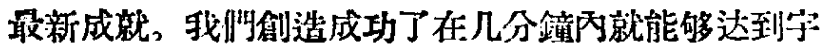
宙速度的强有力的噍式发动机，制造了最精确的自

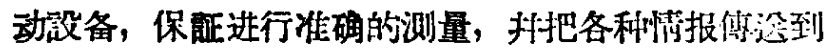
几十万公里的地方。只有技术上最发达的国家开有能 力做到这一切。


联宇宙火箭是在較困难的条件下一一下弦时期发射 的。这时月球位于天球赤道附近。

最便于进行这种发射的时期是新月时期，但任这

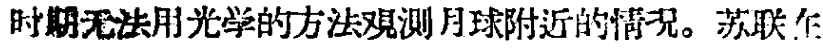
发射这个火箭时月球已經远远地走到南生伥，因此报 好在位于苏联南部——克里米亞、外高加索、中亞絧 们的天文台来观测火管的运行。

为了实現宇宙火筒的发射，不仅需要使这个火简 的速度美不多相当于人造地球卫星所需速度的一借 牛，而且还需要非常精确地計算抹提化这种速度的值 和方向。在計算速度方面有一点点疏忽, 就会使活驗 归于失敗。

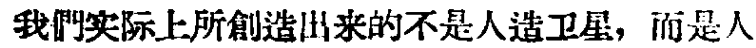
造行星。它所提供的情况都是研究宇宙空㓦物理条作 最㻅費的瓷料。

这次的成就标志荃通过人直接部問太阳系天体的 凃徑来研究这些天体的滇正开端。

克罗什金(苏联物理数学副博士)，苏联第一个人

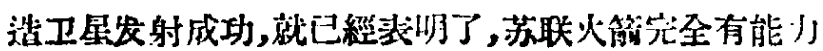

达到月球。根据简單計算表朋，农射第一个卫星使用

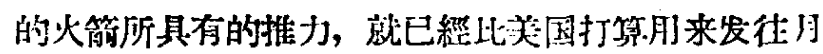
球的火箭大了。但是, 要达到月球还不是那么储篻 的, 筸先必須䛅算山不只是低一个行星引少作用下的 运行的物体的顿道。就这一点上說, 总因官方所发行

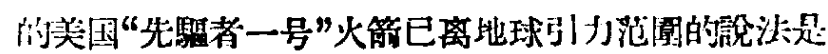
全銷裙的。

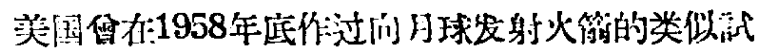
路，但是失敗了。苏联的已飞大宇宙的火簢重量几乎 达一吨作，而美国类似的最大的"月球"火简还不到以 十公厅。

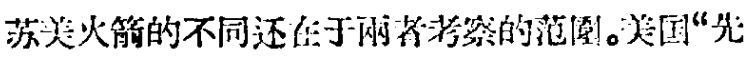

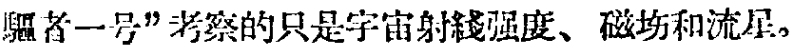

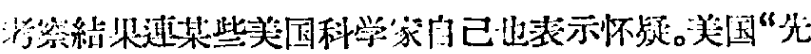

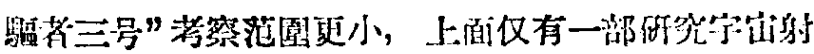

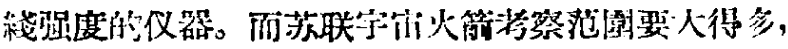

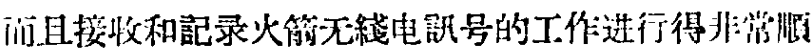



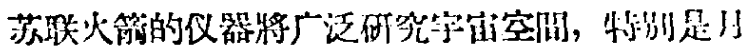
球附近区域。目前极为重要洏们未解决的间题, 是月

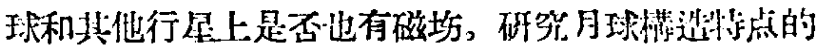

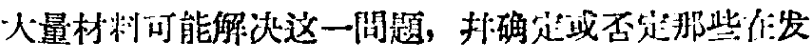



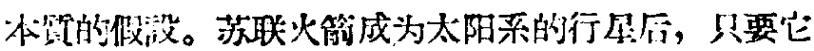

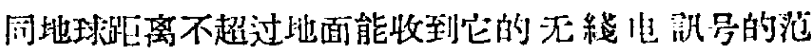
圈，火簿將会提供极为有趣的材料，这將有订能作比




現实的的捉，足以把第一批美国卫星那样的物体㨁人



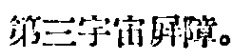

念罗德尼津 (苏联科学院院上): 茄联先迭火简抆


学、热力学、化学、治金学、无紹电工学、仪器制沾、



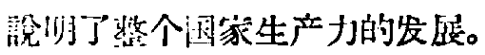

新的1959年以杰的事作俳了自己开始的标诂。

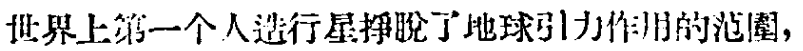

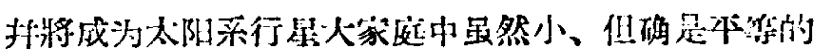

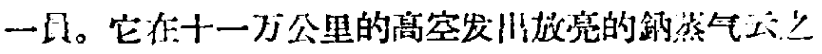

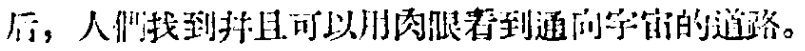

\section{关于紅色宇宙火箭的軌道}

庫卡尔金(苏联天文学家)：苏联发射的第一个人

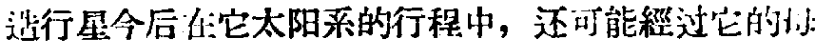
美——地球的身紊, 在地球上将看到这个小行生的叮 能州:是存在的。

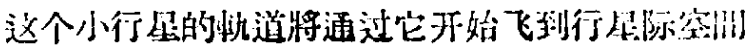


去时的性发点(地球运行軌道上的一点)附近。拉目， 今后它將經常通过这个同地球接近的地区，那时也钎 可以从地球上直接覌等到这个行屈。如果火箭仅仅在 太阳引才的影响下运行, 那么它將十分噍确地回到它 进入軌道时的肘发点上来。但是由于它的运行將受到 太阳系其他天体的影呴, 它只能大体卜:靠近这个收发 点, 未必能回到地球上.来。

斯特态菲尔德(苏联等埌航行学家)：第一个人造 行星在園繞太阳运行 125 圈以后將回到原来的发射此 点, 排同地球相遇。从理淪上来說, 这应当发生在公

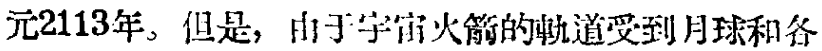
行星影响们发生变化，媇行星將沟有可能同地球机

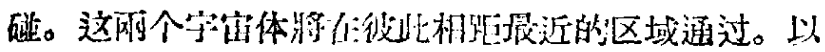
上是以人造行星圈絰太阳运行的閏期正姄为 450 个地 球日为㮛胁，进行䚺算的。

化取近的几十年中，新行星特保1975年初同地球 摄为接近。但就是那时它闹地球的距离世还有 1,500 万公里。1月 2 日从地球发射江的火简, 只要它在运 行中不遇到任们䉥碍的話 (这里浚有把各行星的影响

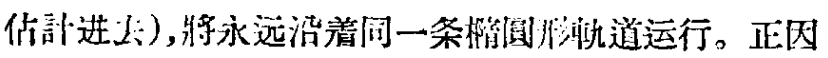

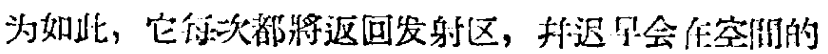
这一点与.阔地球相遇。

450 天 以后苏联人造行尾义將回到战球軌道上发 射人造行屈的区域。但是那时地球朴身文沿着自己的 胅道向前走得很远了, 它距新行星的距离將沅远超过

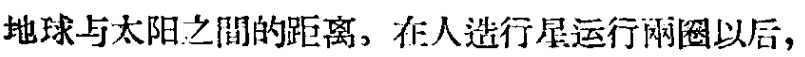
这个距离还会加大: 它捫的位置將正好是一个任太阳

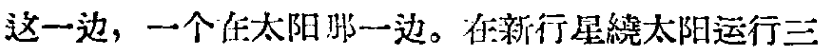
圈和则图原, 它同地球湖此离分别为 20,000 万公里和 6,700 万公里。

达达耶夫(苏联普尔科沃天文台学术秘書)，茄联 人造行星往:五年一次通过离地球极近的区域，这时利

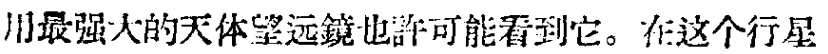
离地球距离等于月球同地球距离时, 它的完度相当于 一个十五到十六等星。

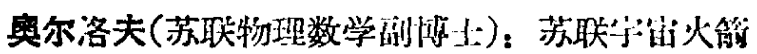

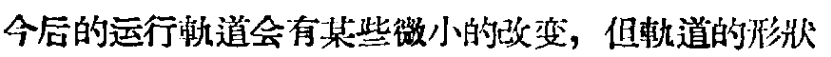
和位置几乎是固等的。

宇宙火箭周夆的环境对火劄的帎道有影响, 但这 种影响也是微不足道的。因此火筒沟寿命实际上將是 无限展的。它可能会遇上流星的摛古, 但微小的流星 体对火箭不会有任何影响, 遇到大流星的可能性:是极 小的, 因此火箭被流星撞毁的可能性在实际上是不会 存在的。和一切沿着轨道运行的天体一样, 火筒运行 的速度也会有所改变, 在近日点 (軌道上，离太阳最近 之点) 时火简运行速度的为每秒 32 公里, 在远 日点 时它的速店約为每秒 24 公里。

\section{宇宙火箭使人类开始能遖接确究 宇宙空間和各种天体}

布拉同拉沃夫(見前)：苏联科学家的目的排不是 要使火箱落到月球上。火箱傒我阿所顷想的那样, 經 过月球附近区域所获得的简报（月球的磁㘯和）球的 收射性) 比火简遖接落到月球上可能获得的情报范圈 要广。关于使火籍落到月球上和创造人造行全哪个近 为重要些的问題, 如果从瑟人听聞约角度来玨, 可能 足有笔論的。

发射月球火皦的另一主要任务是，获得有头摆肌

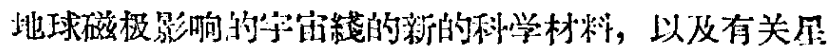

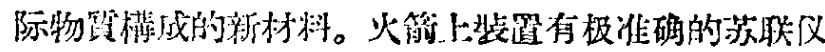
器, 它坷以第一个回答月球磁极是否存在和月球洨行 䖝射能的闻題。

庫卡尔金(兒前)，第一个宇宙火简的任务不是降 落在月球上。但是使火箭降落在月球，上經是光全可 能的。

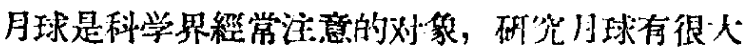
价值，因为目前找們还只了解一个星球一一地球。胁

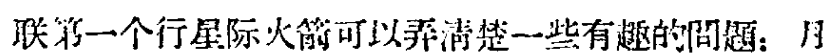
球的磁坋分叫们，月球的放射性如们。这些䦗题的解

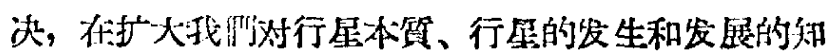
識方面，有很大价值。

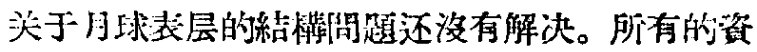
料都有利于認为月球表面实际上盖着一层緍小粉朴

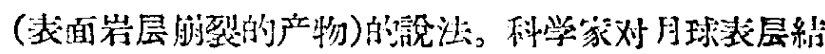

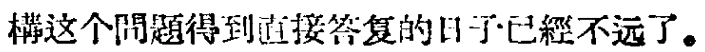

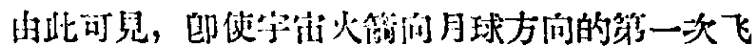
行, 也就有助于于解决一系列天文学阙題, 这些问題对 进一步的宇宙飞行以及对認㖪行显发展的过程都有着

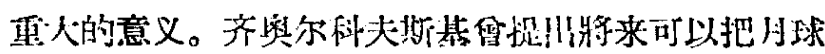
作海行星际飞行的萑标起飞㘯这个有名的思想。的 确, 离开月球不需要克服磁密的大气，因为球上笑 际不份在大气；近不需要使火简达琲方秒11公里以上。 的速度, 因为球的引方只是地球引力的 $1 / 6$, 对于-



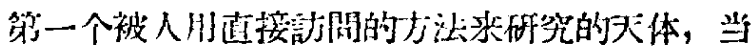



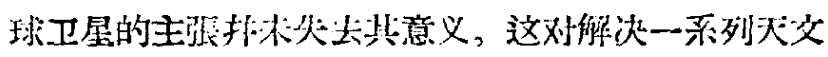
学洞題有芸了大意义。

任最近年代就可以川淔接到月球上出的方法来研 笁月球。同时近可以发射一个月球卫星。这是不相难 的。

費登斯基(苏联国际地球物望年禁員会委貝)，現

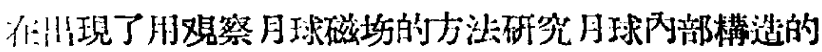
叮能性，这是一个有巨大重要意义的事实。仅仅从洲 月工磁坛的研究中就可以判断月球队部棈造如们，它 
是否有与地球核心相问的核心。一般諰为地球磁源在 地球核心中。关于月球內部自然構造的概念对認識地 球历史各个时期是非常重要的。苏联地質学管認为, 月球发展的历史与地球的地質历决非常相象, 例如在 月球表面也可以发現造山运动的遗迹, 火山爆发的痕 迹。列宁格勒科学家科齐列夫最近甚至发現了月球上 的活火山。月球和地球无具有共同的起源和共同的 字宙历史。从字宙火箭上获得的資料可以製助洞吸对 这些佮末朋确的問題的潧相。

科者列夫(苏联天文学家，物理学家)：月球上的 若干秘密在最近將来垖可揭獟。偕助宁宙火简的考察, 月球是否有自己的热輻射問題郎河得 H 熶后絬諭。

第一个宇宙火简所摧帶的仪器將帮助对那些用具 有极高的科学精确性的天文然远篭也无法解决的問題 得到答案。

到目前为止，月球的表面被認为是统算着厚厚的 尘层。如果月球上火山活动还很强烈, 筫归到月球 表面的揢岩就会分离时在月球深部被吸收的气体，結 果在月面上就会形成导热能力微弱的多气泡物質。末 来的宇宙火箭將会对这一設想得到証实。

阿尔偑尔特(苏联地磁学整家)：苏联宇宙火箭上 的仪器有足够的灵儌度, 来测定在相当远的距离上地 球磁坊的炥弱和測知月球区域的磁性。

遖到目前为止，除了地球以外，只在太阳上发現 了磁性現象。然而无淪是地球的磁性，还是太阳的磁 性，到目前为止都还不十一分清楚。可能，地球上和太 阳上的磁㘯来源不同，因为太阳是一个熾热体，在它 的表面上发生强有力的电磁过程。这种过程本身会产 生出强有力的局部性的磁㘯。到現在还沟有升清楚, 太阳作为一个宇宙体是否具有磁坋。考祭在寒椧的 “死宛的”月球上的磁性就能够解决这个謎。

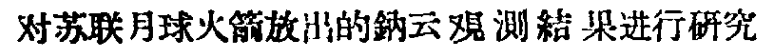
原，就能够得到行星际物资染度的重要資料。这种人 造彗星的高度和大小的变化同周圍介翼的彇态一一问 星际气体的综度和質量有遖接关系。

火筒上的仪器將可能确定行星际气体的化学成 分。这对于精确地計算未来无人駕咦字宙飞船的飞行 軌道和它們的速度具有巨大的意义。特别是，这將有 助于更准确地向月球方向发射下一个火简。

哈巴科夫(苏联月球地質学家)，科学家利用学访 火箭来完成的新的研究任务时, 將得出关于流星物質 数量和組成的可点估計，这些流星物签对于宇宙飞船 有一定的危險，可能月球表面相当大的一部分疏松的 浮上就是由它狮組成的。

只平科夫(苏联科学院院士)：直接在行星际空間 确定源始宇宙杫中重原子核成分的强度和数量也是非 常重要的。如果在那里重核元素同留于(郎氫核)的比 列同在恢星际空閒所发現的一样, 那么可以認为, 宇

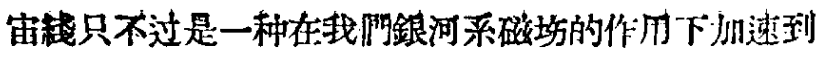
几乎达到光速的怕星际物望。

大气层从地球延伸蛙去的距离此直到現在一般人 所認为的要远得多, 要解决这个间题, 必須把火渻发

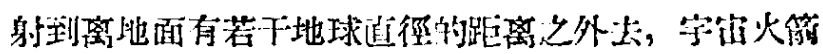

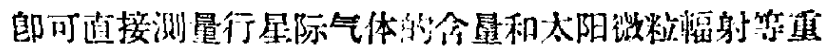
要的材料。

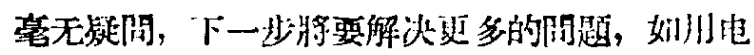

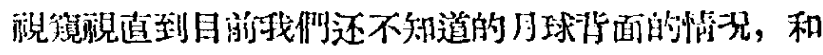
开始之拜訪太阳系的其他宇宙体管。

列別金斯基(莫斯科大学教授)：最近利川人滥地 球卫星发現，在地球周圍存低着被菂束在地球磁㘯门

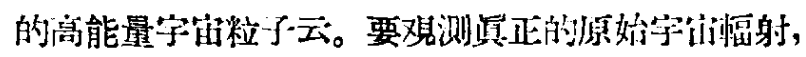

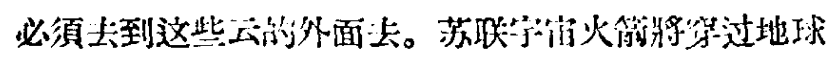
磁坊，因此宇宙火籍將穿过地球附近的宇誼粒子”云。 此外，火简还可能发现作太阳系中聚集的粒了。

多罗德尼津(苏联科学院院上): 人类已經盼到了 “字宙学偉大的发現”的前多。要探索月球和宇宙奥 秘，就必須着手完成例造运械考祭队的宇宙飞船，这 就是自 1957 年 10 月 4 日所开始的研究工作的目的。 要实現这个任务, 当然还需要做訢多已大而文网难的 工作，但是可以这样說，这項工作已經从摸索、探水 的阶段轉入了技术設計的阶段。

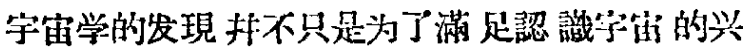
趣。它是有重要实际价值的。例如研究宇宙輻射、微 粒輻射对認識物筫構造就有重要的伦圳, 而且这些研 究工作已經对利用核反应过程有了这接的資献。

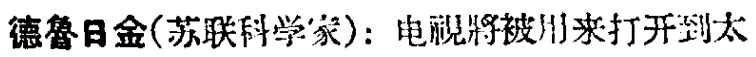
阳系其它行星击的道路。在惐人的火简飞化球和其 他行星以前, 可能將首先考然它陮的表面, 未洗定科 学仪器和人在这些星球上都陆的最方便的位置。

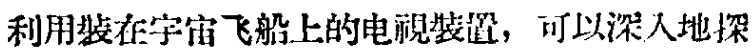

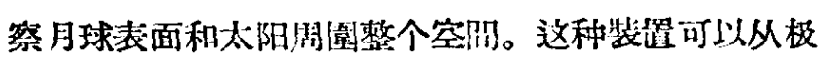
近的距离观测月球和行星表面, 排将考察絡果以普通 电視形式发回地球。訂算表朋，月球轉播电視的激晰 程度比地面电視中心的电浣发爷莹不了多少。

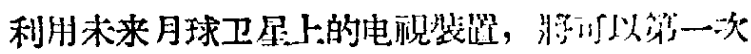

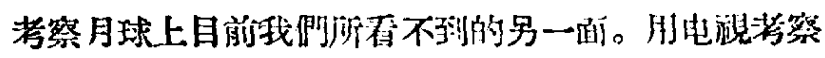

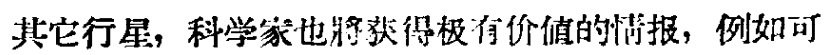
以第一次呵确回答有关火小的生们形工和在金星表 面着陆可能性的問題。

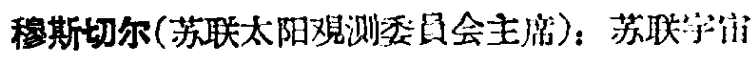

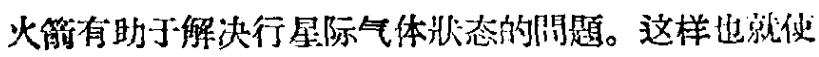

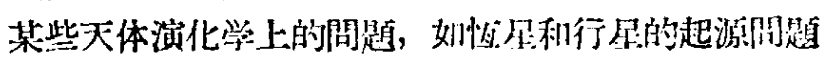
接近解决。火等将去探测月球磁坊。这次发射火簿北 能証实天体磁坋与其自轉有关的假役。

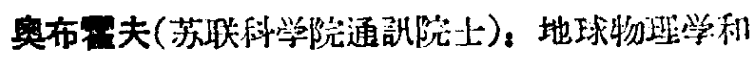
天文学的界限正在消失。获联科学家們所制造的特种 
议器, 將用来研究行星际空間的性望, 行星际空间战 不象很久以前所認为的那样“空”。这次发射宇宙火箭 是人类第一次用研究地球的仪器去研究天体, 首先是 我們最近的鄰居一月球的物理性筫。

普什科夫(苏联散授): 宇宙火箭所載的仪器中， 有一种持殊的仪器, 它的使命是, 回答月球是否有磁 㘯, 这个磁坊的范圍文有多大的問題, 这个問題很久 以前就引起了学者們的兴趣，但都沒有找到答媳。考 察和测量月球磁坋只能用在月球上或是在它附近的磁 性仪器子有可能, 而苏联宇宙火箭就第一次地提供了 这种闭能。

阿姆巴楚米揚(苏咲科学院院士)：在一些被称为 “不稳定星”的恆星上发生爆发时，常常可以釋出此氞 彈爆炸时产生的能还要大几十亿倍的能, 什么自然过 程会导致这类爆发呢? 研究这个間題无疑会揭示自然 界許多新現像和新規律。苏联在制造考察朋宇宙火筒 方面的巨大成就將大大抓速这个問題的解决。

研究宇宙在現代科学中佔越来越重要的地位。通 过对行星际空間、㤢星和星云上发生的物理过程的研 究, 我們就有可能发現一些直到目前仍琴不清楚的一 些物質特性和自然界規律。

所請不稳定星也是我佃研究的对像。現在已經厂 清, 这些星所获得的能量有相当一部分具有不发热的 起源。此外証明，这些能常常是在这些星发生爆发时 裂们的。这种爆发的原因佾待考察。

苏联向宇宙空間发射火筒的意义不仅在于人所椡 造的宇宙飞船第一次冲出了地球引力氾圍, 而且它为 叹得关于“行星际空間、关于月球的物理特性以及关于 宇宙總的材料开創了可能。人类自己踏上月球, 然后踏上，具他星球的时间已䌈不远了。

\section{展望星际旅行}

沙罗诺夫(苏联物理数学情士)：苏联守宙火箱是

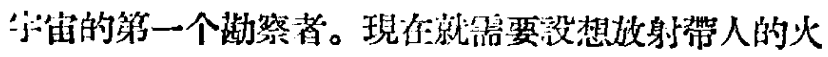
简到宇宙航程中去了。人类到月球上去是我們这一代 的任务, 整无教問, 不久的將来就会解决这一任务。

菆根松(苏联利沃夫大学天文台台長)：荕联科学 家現在已經能够有把握地計划问太阳系中任何区段从 事行星际飞行,要飞多远就飞多远,有一切根据認为, 苏联第一批行星际旅行家在太阳系中离我婀最近的一 些天体上着陆的时間已經不远了。苏联向月球发射字 宙火箭意味着，現在我們可以脽何一种事先顷筧的 軌道曲綫来发射火箱。

什馬科夫(苏联电視业家)：茄联字宙火箱发射成 功及其噴㳩了鈵云表明, 宇宙电視——问地球刚牛球 轉播电峴的問題垖將得到实际解决。

利用宇宙火箭造成了人造云, 这是有重要意义 的。人造云可以用来向地面反射无綫电波。只要有兩
个每24小时繞地球运行一周的这样的云就足以向全地 球轉播电視了。

苏联第一个多級宇宙火劄发射的意义，在目前㨁 至很难旮分地意識到，很 难 想象它对人类的整个影 响。但有一点是无可怀疑的，这是走问人飞到其它行 星歨的堛敢的第一步。剩下的就是解决宇宙飞船順利 回到地面和载人的火箭飞行的問題了。这个問題一解 决，人类关于行星际旅行的理想就將实現了。

納女(苏联爱沙尼亞科学院院士): 苏联这头向月 球发射火簡，尽管这一事件在原理上讲非出乎意料之 外, 但它仍然引起人们的惊喜, 特别是宇宙火箱最后 一級的重量。过去馨家們認为, 月球火箭的有效载重 將是几公厅, 最多也不过几十公厅。阿事实却超过了 一顾最乐观的渞料。这再一次証岄，如果生物返回地 球的䦗題得到彻底解决, 那么人类的宇宙旅行將成为 完全可能了。估計在六十年代的前五年, 也就是在苏 联七年計划完成之前, 人就有可能从事宇宙旅行了。

苏联宁宙火简的发射在研究空宙方面迈进了极重 要的一大步。发射圍繞月球运行的人造卫星以及使它 浩着月亮和地球的共同軌道运行, 已經成为可能的事 情了。如果把苏联第一支发向月球区域的宇宙火箭的 准效重量减小，那末这支火箱就可以向火星发射了。

多勃隆拉沃夫(見前)：随着苏联向月球方向发射 火箭成功, 开始了在征服宇宙空間方面的新阶段一 行星际交通的阶段。

这一次苏联宇宙火筒的发射过程本身、火箭沿轨 道运动的性筫、火简上的呚备以及火简飞行期間发生 的訴多重要現像都表明，現在有完全現实基础发展行 星际交通, 在极近的將来, 人就可以正正踏上其它行 星的表面。为了实現行星际旅行, 苏联科学家和工程 师已經完成了最主要的事情, 他們例造了能够使火箱 获得第二字宙速度抹从耐使其眖离地球引力坊和达到 太阳引力㘯的发动机。

下一个重要的問題就是发射一种可以回到地球上 来的人造地球卫星。为此需要一种稳定系統, 使卫星 同地球保持一定的相对位置。还必須有一种在卫星飞 入地球大气层时城刹卫星速度的㱔温。在这一方面的 第一步已經完成了。苏联科学家问四百多公里的高空 发射了一个火箭。这个火筒是稳定的, 它没有橫向的 旋轉，井且完整地回到地球上来。

另一个最重要的和㙍有意义的任务是: 呼觉使人 能够在宇宙空間生存的条件, 抹且在火籍上創造这种 条件。目前在火箭容器內部已經人工造成了所有仪器 和机組正常工作所必要的像条件, 溫度和压力在飞 行期問一直保持在一定范園内。显然可以湏期, 在不 久的將来也可能造成保証人在宇宙飞船內生存所必䨐 的适当的气候条件。

此外，鈘蒸气在字宙空間不分离的事实使找們可 
以提出一个榈題：特来是否能在宇宙飞船的周圈造成 地球大气层。如果能够，那就將大大便于人的行星际 行了。

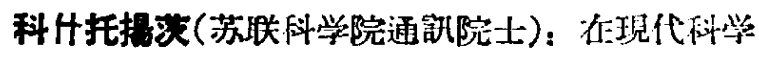
技术水不的情况下，人类可以克服生理条件不适于在

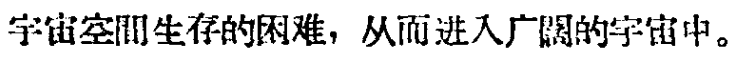

第一批可能拄在月球上或者其他行星上的人，

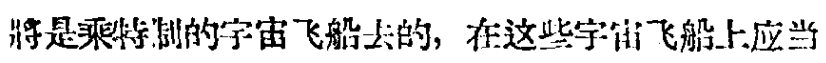
灰虑装上一些能够刢造基本生理过程㭁非常适应的一 切条件的没备。这利飞留鬥是同大地球有經常联系的 “小地球”。在这种飞船上，应当有許多殿备使人們在里 头能感到象生活在家里一样, 抹能在其中进行观测。

加津科(苏联医学家)和馬尔金(苏咲医学家)：湘

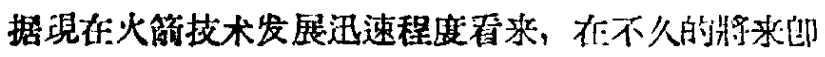
將开始人在宇宙空間的飞行了。第一批宇伯飞行家一 分可能是老継的試飞員，他們能在情楮极其紧張时保 持高度的工作能力, 在不平常的和不断迅速变化的飞 行条件下, 迅速作出正确决定。

从已获得的材料可以得计結諭, 动物们以㴖意地

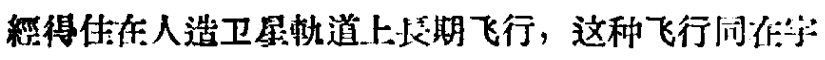
训中飞行的条作是相近的。川动物进行医学一生物学 研究的下一个必要阶段, 就是建造可以保跴诉驗动物 回到地面的人造卫星。

在宇宙空間的飞行, 不仅会大大㞦强人的生理上

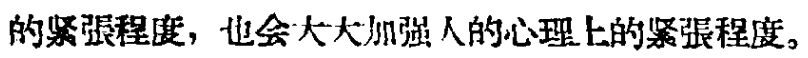
在头几次行䁷际“旅行”中，这种紧張是特别强烈的。

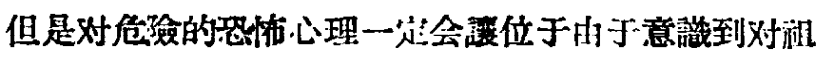
国的职責和在宇宙中飞行对全人类的巨大科学意义而 产生的离昂热情。

虽然字宙生物学在岡㴊不久以前才产生, 但現低 其研究沦图已經广泛了。它所研究的重大間題包括, 研究各种各样往往是不斗常的外界因䇣对活机体的影 响; 找寻在字宙飞行条件下和在其它行星上維持正常 生仰活动的方法和手段，研究可能存在于其它世界. 的生活形式等。

保証人在宇宙空间飞行期间正常的生命活动, 是 守宙医学(宇宙生物学的一个部鬥)的基本任务。这一 忊科学在近几年来得到特别迅速的发展。

宇宙医学的研究，目就点本上按兩个方向发展。第 一是实驗室試驗，仿造宇宙飞行的各别因䇣如加速 度、层湯、低压、在隔绝的小屋內長期居留等等的 影响。第二方面包括火箭、同溫层气球和飞机上的医 学一生物学研究。

克拉特(苏联普尔科沃天文台太阳物理学部主 1T:)：苏联人造行星是建造經常園絸太阳运行的巨型

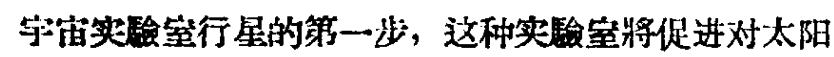
的研究和对太阳系行星的丁解。

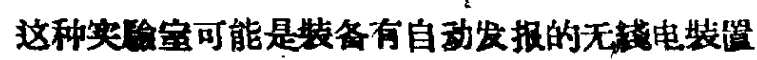

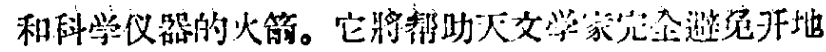


收扑使形象变殁，妨碍对行星的光兴观测。

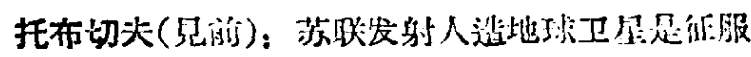

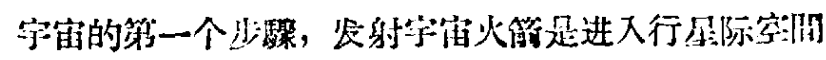

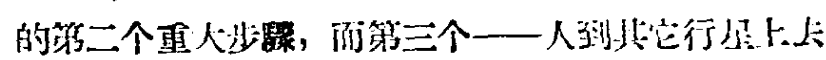
的垌話般的飞行, 世印將珹为現笑。

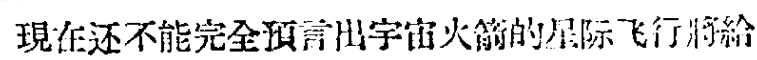

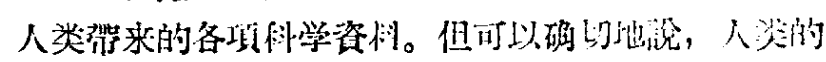

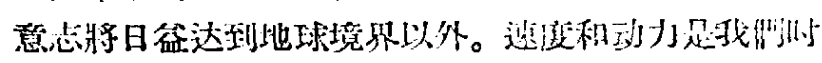

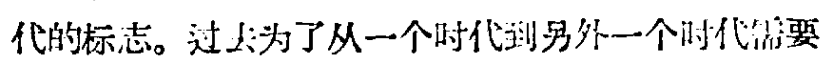

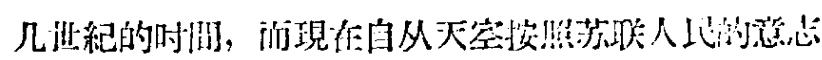

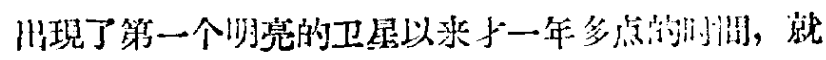

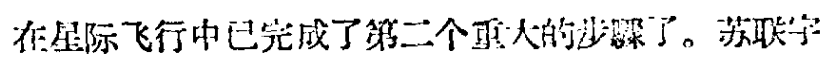

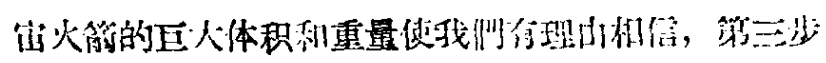
世將成为現实。

\section{关于开发月球和行星}

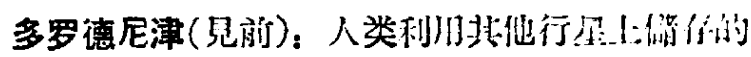
叮能比地球上还要多的各种稀有元䒺的没想, 䋓不是

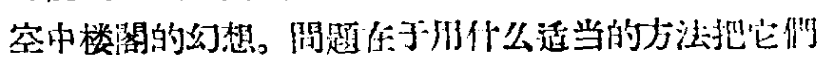
运到地球上来。当然人类究究会在其他行星上:发珿多 少新东西, 我们还没法猜测, 但嘉无疑問, 人类是会 很好地利用这些䉼紧現的。

夏罗諾实(苏联科学家)：未来的月球惊是一个拥 有科学站、工厂、矿山和大居民点的繁荣些界。㘼 来, 人类必然可以居们到太阳系的其他行星上，如赑 不是所有行星都能付到，驻少可以住到部多行足上 去。

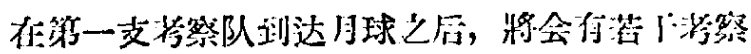
队総緛开往月球，在那里將会建起永久的科学站、天 文台，工作人员居传在湾阴的倛所里，他們所需的



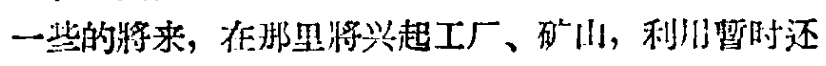

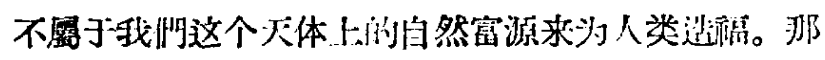

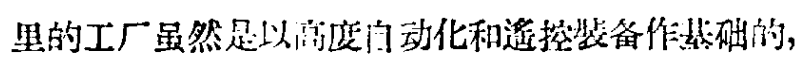

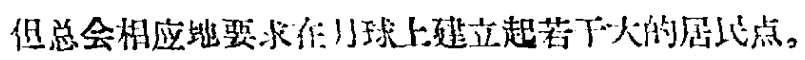

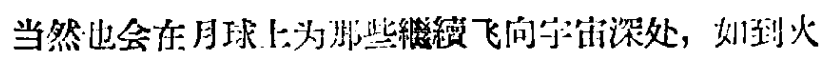
星、金星上法的火简建设起中间州油站。

可能有人認为这只不过是一种幻想。哭于这一点

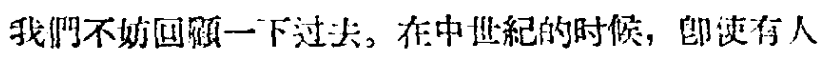
仅仅談到現代的城术，莎到有几百力八口的工浆中

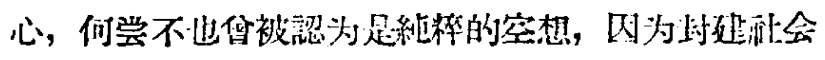

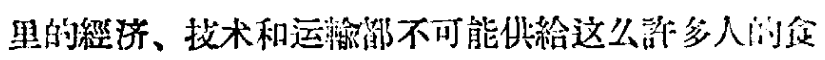

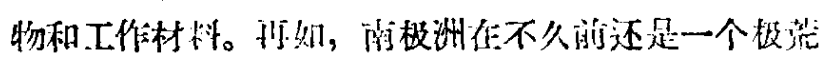

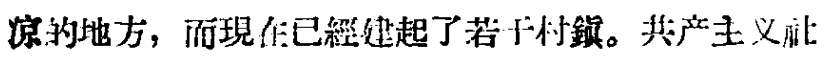
会的找术一定会管全克服人类作月球居留时可能偲到 的一步困难。 